\title{
LA FIESTA DE UN PAÍS NORMAL. LA DISOLUCIÓN DEL 2001 EN LOS FESTEJOS DEL BICENTENARIO
}

\author{
Party of a Normal Country. The Dissolution \\ of 2001 in the Bicentennial
}

\author{
María Repupilli \\ mariarepu@gmail.com \\ Universidad de Buenos Aires \\ Pablo Brambilla \\ pablobrambilla@gmail.com \\ Universidad de Buenos Aires
}

RESUMEN: Entre la crisis político-económica del 2001 y los festejos oficiales del Bicentenario argentino en mayo de 2010 nuevos discursos instituyentes y hegemónicos convirtieron la «crisis» en «normalización», y la insurrección en tradicionales modos de hacer política. Parece condensarse en dichos festejos una nueva etapa y un modo oficial de representar la historia, re-inaugurando en el marco del Estado-Nación un nuevo equilibrio social en el que los conflictos han quedado en el pasado. Pero, si consideramos que el Estado-Nación y el sistema de intercambio capitalista llevan intrínsecamente a la desigualdad y a la represión de unas formas de representación sobre otras, aquel equilibrio social se vuelve tan sólo una forma arbitraria de nombrar la realidad. Por eso, se hace necesario desmontar esas expresiones simbólicas dominantes que nombran u omiten expresiones políticas como aquéllas iniciadas en diciembre de 2001, y así desentrañar algunos interrogantes: ¿cómo aparece el pasado reciente, y en particular la crisis del 2001, en el discurso originado desde el Estado nacional argentino en el último periodo?; ¿qué lugar ocupan hoy las experiencias políticas que en aquel momento se originaron?; ¿qué se recupera y qué se intenta dejar en el olvido?

Palabras clave: política cultural, hegemonía, crisis 2001, Bicentenario argentino. 


\begin{abstract}
Between the political and economic crisis of 2001 and the official Argentine Bicentennial celebrations of May 2010, new hegemonic, instituent discourses turned the crisis into normalization, and insurrection into traditional ways of doing politics. These celebrations seem to mark a new stage and a new official way of representing history, re-opening a new social equilibrium within the frame of the nation state in which conflicts have been left in the past. However, if we consider that the nation state and the capitalist system of exchange inherently lead to inequality and the repression of some forms of representation by others, this social equilibrium is no more than an arbitrary way of naming reality. It is therefore necessary to remove these dominant symbolic expressions that name or omit forms of political expression such as those initiated in December 2001, and in doing so, pose some questions: How does the recent past, particularly the 2001 crisis, appear in the discourse emanating from the Argentine national state in latter years? What place do the political experiences that originated at that time occupy today? What is recovered and what is being pushed into oblivion?
\end{abstract}

KEYWORDS: cultural policy, hegemony, crisis 2001, Argentine bicentenary.

RESUM: Entre la crisi política-econòmica de $2001 \mathrm{i}$ les celebracions oficials del Bicentenario argentí al maig de 2010 nous discursos instituents i hegemònics van convertir la «crisi» en «normalització», i la insurrecció en tradicionals maneres de fer política. Sembla condensar-se en aquests festejos una nova etapa i una manera oficial de representar la història, reinaugurant en el marc de l'estat-nació un nou equilibri social en el qual els conflictes han quedat en el passat. Però, si considerem que l'estat-nació i el sistema d'intercanvi capitalista porten intrínsecament a la desigualtat i a la repressió d'unes formes de representació sobre altres, aquell equilibri social es torna tan sols una forma arbitrària de nomenar la realitat. Per això, es fa necessari desmuntar aquestes expressions simbòliques dominants que nomenen o ometen expressions polítiques com aquelles iniciades al desembre de 2001, i així desentranyar alguns interrogants: com apareix el passat recent, i en particular la crisi de 2001, en el discurs originat des de l'Estat nacional argentí en l'últim període? Quin lloc ocupen avui les experiències polítiques que en aquell moment es van originar? Què es recupera i què s'intenta deixar en l'oblit?

Paraules Clau: política cultural, hegemonia, crisi 2001, Bicentenario argentí. 


\section{Introducción}

$\mathrm{D}$

os momentos con mucho contraste en la ciudad de Buenos Aires. Un 25 de mayo de 2002 vecinos del barrio de Villa del Parque asistían a una jornada de trabajo solidario, allí había actividades de reflexión con historiadores, teatro, mate y pan hecho en horno de barro, junto a integrantes del Movimiento de Trabajadores Desocupados de Lanús y otras asambleas barriales con quienes se compartirían experiencias y ayuda solidaria para paliar las inundaciones en barrios del conurbano bonaerense. Durante otro 25 de mayo, esta vez de 2010, millones de personas en las calles eran convocadas por el Estado nacional para festejar durante cinco días los doscientos años de la Revolución de Mayo de 1810, el denominado Bicentenario de la Patria, dos siglos habían transcurrido desde que asumiera la Primera Junta de Gobierno y el territorio dejara de ser una dependencia colonial de España.

Qué pasó en aquellos casi diez años transcurridos entre un momento y otro para que se produjera tal contraste: los años 2001 y 2002 habían sido años de crisis económica, estallido social, revuelta política; en 2010 parecían primar la paz social, la convivencia, la celebración. Al menos así pretendían mostrarlo unos festejos patrios que se desarrollaron en el marco de una política cultural más amplia.

\section{De la crisis a los festejos}

Condensadas en la consigna «que se vayan todos», las jornadas del $19 \mathrm{y}$ 20 de diciembre de 2001 dieron lugar en Argentina a novedosas manifestaciones de rebeldía y resistencia que intentaban hacer frente a las consecuencias de un ciclo histórico abierto tras la dictadura cívico militar (1976-1983) y la implementación de las políticas económicas neoliberales propias de los años 90: altísimos niveles de desocupación, pobreza, recesión económica, graves problemas educativos y nutricionales en gran parte de la población. El cuestionamiento social había llegado incluso a las formas mismas de representación política propias de la democracia post-dictatorial: deslegitimación de los tres poderes, de las estructuras políticas partidarias, de las organizaciones sindicales, descreimiento en los medios masivos de comunicación. Ante esto 
surge la multiplicación de esfuerzos por construir experiencias de democracia directa, reivindicación de la horizontalidad, presentes en la recuperación y autogestión de empresas, asambleas barriales, clubes de trueque de productos de consumo cotidiano, movimientos de trabajadores desocupados, campesinos e indígenas. Experiencias que en definitiva supieron combinar emergencias económicas con expresiones políticas que, en su conjunto, se expresaron de un modo inédito en la historia de la Argentina.

Cuando dichas jornadas se sucedieron la sociedad argentina enfrentaba, por el lado económico, endeudamientos millonarios con organismos de crédito internacionales, recortes del gasto público, déficit fiscal, emisión de bonos, recortes en salarios y pensiones, crecimiento del índice «riesgo país», fuga de capitales y la decisión de restringir la cantidad de dinero que las personas pueden retirar de las entidades bancarias (el denominado corralito). Por el lado político, resaltaban la sucesiva dimisión de ministros y funcionarios, y el acatamiento absoluto a los pedidos del Fondo Monetario Internacional (FMI). Los resultados condujeron a la profundización de la pobreza y de los niveles de desempleo, y las respuestas de la población fueron saqueos (especialmente en el conurbano bonaerense) y masivas protestas (en las principales ciudades del país) que llevaron a la declaración del estado de sitio el 19 de diciembre y que dejaron 39 personas asesinadas por las fuerzas represivas del Estado. Tras un ineficaz intento de lograr un gobierno de coalición con el peronismo renunció el entonces presidente Fernando De La Rua y luego vendría una seguidilla de asunción y renuncia de cuatro presidentes, hasta que el 2 de enero de 2002 asume Eduardo Duhalde quien gobernará hasta la asunción de Néstor Kirchner, 17 meses después.

La mayor parte de los participantes en las protestas que se sucedieron durante las jornadas del 19 y 20 - pero que continuaron durante los meses siguientes bajo la forma de «cacerolazos»— fueron autoconvocados que no respondían a partidos políticos o movimientos sociales concretos. Esto daba lugar a la aparición en el país de la discusión en torno a las ideas de autonomía, autogestión y horizontalidad.

Posteriormente la crisis pudo ser disciplinada y controlada. Primero a través de la represión directa en el marco del gobierno de Eduardo Duhalde (2002-2003) que tuvo su mayor expresión en el asesinato de dos militan- 
tes sociales en la denominada Masacre de Avellaneda. Y luego, a partir de la asunción del gobierno de Néstor Kirchner (2003-2007) y la continuación de su proyecto político en manos de Cristina Fernández (de 2007 a 2015), a través de la recomposición de la gobernabilidad, reorganización del bloque de poder, inclusión económica a través del consumo, otorgamiento de planes sociales, disciplinamiento y cooptación de organizaciones sociales a través de la intervención estatal. Kirchner se basó en una relación estratégica con los movimientos sociales: comprendió que no debía desestimar la herencia que había dejado diciembre de 2001 e implementó políticas subsidiarias que decían «apoyar» a los movimientos que en ese momento habían nacido, facilitando la reinstalación de la política tradicional (delegativa, jerárquica, representativa y clientelar) pero esta vez montada sobre organizaciones populares. Se decía intentar el sostenimiento desde el Estado de la autogestión, pero en muchos casos el único resultado era el desmantelamiento de estos espacios colectivos o bien lograr desvirtuar su dinámica, ya sea a través del otorgamiento de subsidios o maquinarias, o bien a través de la instalación de la figura del puntero político que provocaba enfrentamientos y desacuerdos internos. La política de Kirchner apuntó a encapsular a las organizaciones piqueteras críticas y reorientar los recursos hacia las organizaciones piqueteras «amigas». La apropiación que éste hizo del discurso crítico interpeló fuertemente al conjunto del espacio militante que venía luchando contra las políticas neoliberales. Esto derivó en la institucionalización de varias organizaciones piqueteras y la incorporación de sus dirigentes al Gobierno, sobre todo en organismos ligados a la acción social y comunitaria, llevando a que en muchos casos compartieran espacios de poder con funcionarios anteriormente ligados al menemismo o a lo más rancio del aparato del justicialismo, sectores con los cuales consideraban que entablaban una «disputa de poder» (Svampa, 2009).

\section{El 200 I, violencia y billetes}

Si volvemos al 2010 y sus festejos del Bicentenario, podemos preguntamos entonces cómo aparece todo aquel pasado reciente, y en particular la crisis del 2001, si tuvieron algún lugar aquellas experiencias políticas origina- 
das en ese momento, e intentar responder así qué se recupera y qué se intenta dejar en el olvido.

La realización de los festejos tuvo, entre otras muchas manifestaciones, un especial interés por mostrar la historia argentina. Durante los cinco días en que se desarrollaron los festejos tuvieron lugar una gran cantidad de actividades - paseos con puestos regionales, desfiles militares y de colectividades, desfiles de autos, recitales musicales, inauguración de galerías artísticaspero hubo dos instancias centrales que demuestran aquel interés por revisar la Historia: el desfile artístico-histórico (presentación de 19 escenas móviles armadas como «carrozas» por el grupo artístico Fuerza Bruta — considerado vanguardista por el discurso mediático - que trataban sobre distintos momentos históricos o descripciones de la argentinidad) y la proyección de imágenes en el edificio del Cabildo (mediante la técnica de video-mapping). Allí se resaltaron momentos considerados cruciales desde la perspectiva del grupo organizador, la denominada «Unidad del Bicentenario», creada desde el Poder Ejecutivo e integrada por unos pocos miembros a cargo de tomar las decisiones.

Al prestar atención allí, llama la atención que uno de los acontecimientos que mayor peso tuvo en la historia reciente, aquélla considerada comúnmente como «la peor crisis de la historia argentina», aparecía diluida, casi inexistente, distorsionada: sólo se asomaba claramente su dimensión económica y los efectos negativos que tuvo sobre la población. Así lo mostraba la carroza de «Las Crisis», que exhibía a personas colgando de un lado al otro mientras intentaban atrapar billetes que volaban por el aire, personas de pie que levantan lo que quedaba en el suelo. Lo sucedido se reducía así a un problema de billetes y el hincapié estaba puesto en el despilfarro financiero, la especulación, la desesperación de las personas por asegurar su estabilidad económica, en una clara alusión a lo que fue el denominado «corralito», aquella disposición que en diciembre de 2001 prohibió sacar el dinero de los bancos por parte de los ahorristas. Por otro lado, si bien el orden cronológico de esta carroza podía remitir directamente al 2001, la puesta en escena no mostraba individualizadas las características particulares y el momento histórico específicos de la crisis. Su dimensión política fue aquí totalmente inexistente en pos de una representación de la dimensión económica. Se volvieron invisibles 
los sujetos y las experiencias que en aquel momento respondieron a la crisis desde la construcción de organizaciones que no sólo se dedicaron a protestar, sino que también propusieron respuestas que se alejaban de los modos tradicionales de hacer política. Y si bien durante la proyección 3D en el Cabildo, el 2001 aparece representando mucho más concretamente y parecía asomar ahora sí su dimensión política, lo hacía a través de las imágenes de la represión policial durante las jornadas de protesta y la respuesta con piedras por parte de la población, reduciendo así lo sucedido a un problema de violencia. Otra vez, no aparecía la puesta en práctica de creativas soluciones de tipo territorial y comunitario, por fuera de los sindicatos, los partidos políticos y el Estado, en manos de sujetos que confrontaban con él pero sin intentar disputarlo, desde relaciones sociales horizontales y solidarias. Nada de todo esto podía adquirir visibilidad. La crisis sólo podía tener el sentido de un sistema que deja de funcionar, se desestabiliza y deja un vendaval de consecuencias negativas, pero nada nuevo ni positivo podía surgir en ella.

\section{El desfile y su más allá}

La disolución simbólica del 2001, en tanto proceso que desdibujó en la memoria histórica colectiva la totalidad y la complejidad de los sucesos que le dieron forma y por medio del cual se evocó un recuerdo parcial y fragmentado, haciendo justamente que su fuerza política quede diluida, fue posible por la vigencia de un relato propio del revisionismo histórico, presente en los festejos pero también en toda la política cultural propia de los gobiernos de Néstor Kirchner y Cristina Fernández. El revisionismo presupone que existe una forma generalmente aceptada de entender un proceso histórico y que hay razones para ponerla en duda. Esta duda se auto-justifica a través de la representación de una historia de luces y sombras, de bandos buenos (aquéllos ligados al pueblo) y malos (ligados a los sectores liberales). Entonces se impone la tarea de revisar la Historia por fuera de los cánones tradicionales del liberalismo y de instalar una verdad, ya definida previamente por un presente político que precisa legitimarse, y según la cual toda acción encontraría su justificación en la asociación del pueblo y el Estado, reafirmando así un estrecho vínculo entre revisionismo y populismo. 
Durante los festejos del Bicentenario, este relato incluyó a la crisis del 2001 al interior de una oscura secuencia de rasgos míticos que se abría con la dictadura militar de 1976, seguía con la década neoliberal de 1990 y finalizaba, como resultado de lo anterior, con la debacle de la crisis del 2001 y sus funestas consecuencias sobre la población; secuencia sólo interrumpida brevemente por la alegría que produjo el regreso a la democracia en 1983. Luego se abriría una nueva etapa en 2003, que superaba lo ocurrido y recuperaba lo mejor de las décadas anteriores al golpe de estado fruto del Estado de Bienestar - que en el país tuvo su expresión durante el peronismo- y el desarrollo de la industria nacional. Rasgos míticos, decíamos, porque en ningún lugar aparecían visibilizadas causas, consecuencias ni líneas de continuidad, sólo escenas pretendidamente contrapuestas. Por ejemplo, durante el desfile las carrozas mostraban momentos de la historia aislados sin una explicación sobre su mutua relación, la mirada del espectador saltaba de una escena a otra sin que nada diera a entender cómo una podía ser entendida como consecuencia de la anterior. Y justamente, el carácter fundamental del concepto mítico es el de ser un saber confuso, formado de asociaciones débiles, ilimitadas, de carácter abierto, lo que permite su apropiación. Se trata de una condensación inestable cuya coherencia es sobre todo de la función (Barthes, 1999).

La narración de la historia propuesta decía recuperar las cosas nunca dichas, aquello que había sido vedado expresar dada la vigencia de una historiografía tradicional, liberal y conservadora, a la cual el revisionismo vendría a completar y corregir poniendo al pueblo como protagonista. Para ello nada mejor que el contenido se rebele contra lo representado un siglo antes en el Centenario, al erigirse expresamente, casi como un eslogan, como unos festejos «populares, federales y latinoamericanos» en contraposición a lo que habría sido «oligárquico, centralista y europeizante», en un actual contexto social de crecimiento económico y libertades políticas, pretendidamente opuesto al de principio de siglo, sin que aparezcan en ningún lado, una vez más, líneas de continuidad o causalidad históricas.

Si bien esta intención revisionista podría hacer presuponer la existencia del debate y disputas por la representación histórica tal como se presentó, los festejos se caracterizaron sin embargo por su tono conciliador (al hacer hincapié en valores como la unión, la alegría, la esperanza y el futuro), carente 
de conflictos (al quedar siempre neutralizados, en el caso que aparezcan, en la idea misma de un Estado-Nación integrador y superador) y capaz de incluir lo tradicional bajo el manto de lo renovador (al incorporar claros ejemplos de tradicionalismo vinculados al discurso patrio y al discurso escolar, como por ejemplo la evocación a los próceres, la inclusión de distintos himnos nacionales dentro del repertorio de los músicos, la constante presencia de merchandising con las enseñas y colores nacionales, los desfiles militares, las manifestaciones folklóricas, entre otros). Al instalarse como la versión más conveniente a los intereses del pueblo frente a una versión liberal y conservadora de la historia, niega en esa misma operación de sentido la posibilidad de que existan otras visiones de la historia. Una visión marxista crítica, podría por ejemplo explicitar las necesidades de un sistema económico capitalista que, siempre junto al Estado, va implementando los modos de representación necesarios a los fines de su sostenimiento y borrando aquéllos que no se ajusten a los mismos.

Si analizáramos los festejos del Bicentenario en tanto signo, éste nos mostraría como significante a «la fiesta», y a la «identidad nacional» como su significado. Podríamos decir que se trata de un signo mítico (Barthes, 1999) porque ese significante borra el proceso de normalización política iniciado tras la crisis del 2001, ignora a los sujetos políticos de la rebelión popular de aquellos años y sólo visibiliza la normalización económica. Este mito es puesto en marcha por el relato gubernamental de Néstor Kirchner y Cristina Fernández. Si expandimos la mirada histórica hacia atrás, podemos identificar como significante a la «gente en la calle» correspondiéndose con el significado «pueblo»y así dar vida al signo Bicentenario. Es un signo mítico porque no muestra el proceso histórico por el cual el pueblo aparece como sujeto pasivo subsidiario de las acciones del Estado, ignora las relaciones desiguales de producción capitalistas que permiten que el pueblo desfavorecido exista en tanto tal, y sólo visibiliza las coincidencias y la participación pacífica en un espectáculo masivo. Este mito es puesto en marcha por el relato del revisionismo histórico.

La puesta en práctica de esta visión de la historia precisó que los festejos del Bicentenario adquirieran la forma y el sentido de un espectáculo, y que se caracterizara por algunas cuestiones bien concretas y cuidadosamente plani- 
ficadas: una concurrencia masiva y aparentemente espontanea, un desenvolvimiento pacífico y unos contenidos eminentemente emotivos, sorpresivos y de alto impacto. La búsqueda por mostrar contenidos de este tipo explica la elección del grupo artístico Fuerza Bruta, calificado anacrónica pero efectivamente como vanguardia, quien generó una puesta en escena que supo combinar todos aquellos elementos en la «fórmula del éxito», a partir de un lenguaje simple, despolitizado, no intelectualizado y con una fuerte impronta tecnológica (presente también en las proyecciones 3-D en el Cabildo). Un ejemplo de entonces puede identificarse en la carroza donde la dictadura militar aparecía representada con una enorme Constitución de la Nación en llamas, símbolo de una democracia que se disolvía al verse suspendidas las garantías constitucionales. A su alrededor flotaba la paloma de la paz, las urnas, la balanza de la justicia y una persona con los brazos en alto rompiendo las cadenas que lo sujetan en alusión a la libertad. El golpe militar quedaba reducido aquí a su dimensión legal ya que no aparecía ninguna referencia a la dimensión política del momento, es decir, no aparecen ni los procesos políticos previos (organizaciones militantes que buscaban la transformación de la sociedad, muchas de ellas por medio de la lucha armada, organizaciones paraestatales como la AAA que buscaban el aniquilamiento de dichas expresiones políticas, por ejemplo) ni lo procesos posteriores (desaparición y tortura de personas, el exilio de los sobrevivientes, la censura por medio del terror, el cambio de modelo económico hacia el neoliberalismo).

A la puesta en escena realizada por Fuerza Bruta, se suma la realización de numerosos recitales musicales que permitieron alcanzar un altísimo nivel de concurrencia al ser protagonizados por artistas convocantes y por funcionar como la antesala del desfile de cierre, de muy alta concurrencia también. La cantidad de personas presentes durante los cinco días de festejos fue estimada por los organizadores en unos 6 millones. Sobre todo se tenía que tratar de un espectáculo masivo que tuviera como destinatario a la gente o al pueblo, indistintamente, a quienes se les dio la posibilidad de encontrarse con manifestaciones tradicionales (como lo fue el desfile de las fuerzas armadas, algo imaginariamente previsto para este tipo de actos) y manifestaciones novedosas (como lo fueron los recursos tecnológicos de supuesto alto impacto, algo imaginariamente imprevisto) de modo de no correr el riesgo de dejar a alguien afuera e indefectiblemente sumar concurrencia. Objetivo que fue alcanzado 
gracias también al negado pero fundamental papel de los medios masivos de información, tanto estatales como comerciales, al darle una amplia cobertura a las actividades conmemorativas y al integrar el tema del Bicentenario a la agenda mediática de los días previos y posteriores a los festejos. Pueblo, espectáculo y masa se unían así en un vínculo que se pretendía obvio y que se expresaba a través de la realización de unos festejos «populares», preparados para el pueblo pero nunca imaginados por el pueblo ni hechos por él, alcanzaba tan sólo con que el pueblo pueda verse reflejado en ellos, identificarse en sus contenidos e involucrarse con su sólo asistencia. La distinción entre productores y destinatarios de los festejos era clara, Estado y pueblo no se confundían nunca: el Estado propone y el pueblo participa como espectador. El espectáculo aquí se revelaba no como una mera sucesión de imágenes, sino fundamentalmente como una relación social existente (Debord, 1967).

Vemos entonces cómo la forma que adquirieron los festejos a través del espectáculo complementa y es funcional a los contenidos seleccionados. Ambos pretenden incluir y escapar de lo tradicional, pretenden ser rupturistas (ya que se autodenominan «vanguardistas») y terminan generando una simulación de la sorpresa al nombrar como inesperado lo que fue cuidadosamente planificado. Decimos que se trató de una simulación porque el espectáculo justamente lo que hace siempre es aparentar la sorpresa pero en realidad ya está hecho para producir una reacción. Es decir, dentro de los objetivos que se propusieron los organizadores estaba previsto el impacto como forma de sorpresa, cuando en realidad ésta pareciera tratarse más de una exaltación de las acciones llevadas a cabo.

Si prestamos atención al hecho de que este formato espectacular no se desarrolló de forma aislada en las últimas décadas, advertimos que es necesario inscribir estos festejos en el marco de una política cultural más amplia, que supo poner a la cultura como recurso de la política (Yúdice, 2002) al combinar una mirada revisionista de la historia, una intención pedagógica desde el Estado hacia el pueblo y por lo tanto performativa de identidades, un uso y una distinción clara entre medios de información oficialistas y no oficialistas de los medios de comunicación, y la intervención de artistas e intelectuales que, como nunca antes, expresaron su apoyo explícito y otorgaron una fuerte cuota de legitimidad al proyecto político en marcha. Se trataría 
de una política cultural que supo poner el acento en un estatismo populista (Canclini, 1987) según el cual la identidad se encuentra en el Estado mismo, más que en la raza, la tradición, la geografía o el pueblo. Allí se condensa los valores nacionales, reúne las partes de la sociedad, regula sus conflictos y distribuye entre los diferentes sectores sociales la ilusión de que son parte de una totalidad protectora, aunque para ello haya sido necesario que la participación popular se reduzca a simple adhesión, las iniciativas populares se subordinen a unos intereses nacionales ya fijados previamente por el Estado y se descalifiquen los intentos de organización independiente. Sin embargo, este estatismo populista presente en los festejos supo combinarse también con el modelo de democratización cultural, al declamar un acceso igualitario a los bienes culturales a través de la gratuidad y la difusión masiva, y con el modelo del tradicionalismo patrimonialista, ya que éste le posibilitó la afirmación del orgullo histórico resaltando hazañas, próceres patrios, tradiciones y el folclore.

\section{El proceso de normalización}

La indagación por la representación del 2001 nos llevó a una pregunta más amplia sobre el modo de representar la historia reciente y que por lo tanto nos hizo observar el pasado. Pero aquella indagación también nos puede conducir a dirigir la mirada hacia el presente y preguntarnos cuál es la lógica por la cual el modelo político-económico puesto en marcha tras el 2001 precisó que la crisis adquiriera la forma que efectivamente tomó en los festejos del Bicentenario. La importancia casi nimia que el 2001 tuvo en los festejos es inversamente proporcional a la relevancia que tuvo en la construcción de legitimidad por parte del gobierno de Néstor Kirchner y Cristina Fernández, ya que el 2001 sirvió siempre para efectuar una valorización positiva del presente en contraste con un pasado de caos y calamidades. Pero para ello fue necesario que el 2001 se hiciera visible sólo en su aspecto económico y en cambio sea invisible lo disruptivamente político: resulta coherente con la lógica interna de construcción del relato hegemónico de este momento histórico que los hechos del 2001 adquieran esta forma precisa. 
El borrado discursivo de la dimensión política del 2001 no significó sin embargo que haya sido ignorado a la hora de planificar los direccionamientos políticos e implementar las medidas de gobierno propias de los sucesivos gobiernos: por supuesto el 2001 se encontraba descarnadamente presente en las políticas de Eduardo Duhalde que buscaban el dominio a través de la devaluación y la represión, pero también se presentaba solapadamente en las políticas de Kirchner que buscaban la hegemonía a través de la represión indirecta, la transversalidad, la cooptación de movimientos sociales y el fomento del consumo. Sin embargo, durante este periodo que llega hasta el 2010 y tendría continuidad, los discursos oficiales borraron siempre la línea de continuidad histórica con Duhalde en tanto que configuraron el 2001 como un recuerdo sombrío que era necesario dejar atrás y que debía ser despojado de aquella política instituyente que buscaba nuevas alternativas por fuera del Estado, los partidos y los sindicatos.

Es que de aquel desplazamiento del Estado de sus funciones expresas, pasamos a un fuerte protagonismo del Estado como promotor de ideas y políticas. Parecía ser el lugar fundamental, casi monopólico, desde el cual pensar la política y las transformaciones sociales a través de sus herramientas habituales: los programas, los partidos, las elecciones, los sindicatos, dando lugar a un nuevo momento de hegemonía y desmintiendo que haya algo realmente novedoso en la construcción política del kirchnerismo. Sucede que para que esa nueva hegemonía pueda ser posible, el discurso del Estado tuvo que mutar algunas de sus características previas a la crisis. Abandonar la coerción directa que vino después y volver a investirse con los atuendos del populismo para empezar, a partir de allí, a tejer un complejo entrelazamiento de fuerzas políticas, sociales y culturales que compartieran la idea según la cual «todo debía hacerse en nombre del pueblo». Si el pueblo había sido el gran olvidado del neoliberalismo, ya que fue la víctima directa de sus políticas, hoy el pueblo tenía que ser de nuevo el gran protagonista pero en tanto objeto de las preocupaciones del Estado, atendido en sus necesidades y reivindicado en el imaginario social. Este cambio discursivo supo convivir con la ambigüedad de un Estado a mitad de camino entre el bienestar y el liberalismo, sorteando las contradicciones entre el protagonismo estatal (re-estatización de algunas empresas privatizadas, otorgamiento de derechos sociales, fomento del consumo, política de derechos humanos ligada a la reparación institu- 
cional post-dictatorial) y el protagonismo del mercado más crudo (vigencia de un modelo económico extractivo y extranjerizante de recursos naturales, centralidad de la exportación de productos primarios, especialmente la soja, una precaria recuperación de la industria nacional a partir de una política de subsidios estatal, y un intacto mantenimiento de las relaciones sociales de producción).

La combinación de estos elementos precisó de un sistema ideológico de legitimación que tuviera al pueblo como significación imaginaria central y, que a través de los festejos del Bicentenario, supiera vincular la historia personal de los individuos con la historia de la Nación a través de una fuerza emocional que actuara de modo inconsciente (de ahí la importancia de lo emotivo y lo tradicional) para juntas conformar la historia de un pueblo unido por la fuerza de una identidad en común (Smith, 1997). Esto implica pensar que ni los símbolos patrios ni la idea de identidad nacional fueron aspectos débiles o críticos en ningún momento del pasado reciente argentino, ni en el 2001 a pesar de la crisis de representatividad política, ni mucho menos ahora en los festejos del Bicentenario. Por el contrario, la idea de un pueblo unido emocionalmente por una identidad construida gracias a la historia en común de una nación puede ser pensada como la línea de continuidad que vincula momentos tan distintos entre sí y que permitió que se desarrollasen, de aquel tiempo a esta parte, los procesos de reorganización estatal y normalización política. Idea, por otro lado, que permitió que tomara fuerza la afirmación de unos festejos que fueron espejo de una sociedad unida a pesar de las diferencias, que supo festejar junta, sin violencia y en paz. La diversidad, efectivamente existente y seguramente contradictoria, se fundió en una idea de nación normal formada por recuerdos históricos, mitos, tradiciones y símbolos colectivos que los desfiles y las proyecciones 3-D supieron reactivar con inteligencia, gracias al papel que previamente había jugado el revisionismo histórico al convertirse en un discurso que no traducía simplemente el sistema vigente, sino en un discurso que era medio y objetivo, en tanto permitía llevar adelante una voluntad de verdad necesaria para el proceso de normalización y necesaria para acallar otros discursos provenientes de las experiencias políticas del 2001 con todo lo disruptivo, desestabilizante o peligroso, también confuso y desordenado, que pudieran llegar a tener (Foucault, 1970). 
A diferencia de aquel 2001 donde la política ahondaba su dimensión instituyente y se desplegaba como momento de autonomía; es decir, como momento de creación de nuevos tipos de sociedad y nuevos tipos de individuos, hoy el Bicentenario profundizó la vigencia de una política heterónoma al negar todo aquello y crear individuos absolutamente conformados, que se viven y se piensan en la repetición de una historia que difícilmente sea la suya en su totalidad pero a la que reciben con la apariencia de una completa espontaneidad (Castoriadis, 1998). Una política que encuentra en la renovación de las ideas de patria, identidad nacional y pueblo la justificación necesaria para que aquéllos que tienen el poder puedan mantenerlo y que intentará formar individuos que las reproduzcan eternamente y, con ellas, el régimen que las ha producido. Sin embargo, la memoria del 2001 podría mantener viva la idea de que la sociedad es auto-creación y auto-alteración, que en algún punto toda estructura está fallada y que, por tanto, todo aquello puede estar destinado al fracaso. En ese sentido, no podríamos decir que el proceso de normalización puesto en marcha por el Estado pueda ser traducido como un punto y aparte hecho por la sociedad, un nuevo fin de la historia realizado por medio de un populismo infinito y un 2001 cerrado en tanto proceso político histórico, ya que siempre la sociedad instituida podría ser modificada por la sociedad instituyente; bajo el imaginario social establecido seguiría estando en juego un imaginario radical pasible de ser puesto en juego nuevamente. Sin embargo, no se trataría de redescubrir unos discursos que están allí esperando ser develados y sus fuerzas devueltas pero sí de encontrar en su entrecruzamiento y su mutua exclusión (Foucault, 1970) con los discursos dominantes actuales la posibilidad de una política que no sea meramente funcional a los intereses de aquéllos que encuentran en el Estado el modo de legitimar intereses provenientes de la maquinaria económica capitalista.

\section{Notas finales}

Este escrito forma parte de las conclusiones pertenecientes a nuestra tesina de grado en Ciencias de la Comunicación de la Universidad de Buenos Aires. La misma consistió en un trabajo ensayístico en el cual cada capítulo contaba con un anexo audiovisual que era al mismo tiempo la base para un 
futuro trabajo documental audiovisual. Como hilo conductor utilizamos los testimonios de diferentes entrevistas realizadas personalmente a planificadores de los festejos, intelectuales, referentes del campo de la cultura e integrantes de diferentes organizaciones sociales con posterioridad a los mismos. Agradecemos en este sentido a todos quienes nos dedicaron su tiempo para reflexionar juntos: Graciela Gurvitz y Daniel Giovaninni, ex integrantes de la Asamblea Popular de Villa del Parque y actuales integrantes de Radio La Colectiva; Raúl Godoy y Omar Villablanca, de la fábrica recuperada FA.SIN. РАт (Ex-Zanón); a los intelectuales Pablo Alabarces, Ana María Fernández, Carlos Girotti, Carlos Mangone y Héctor Schmucler; a Fabio D’Aquila, del grupo artístico Fuerza Bruta; al historiador Felipe Pigna y al funcionario Julián Kopecek.

Por su parte, para la realización del ensayo retomamos textos y teorías de autores provenientes de diferentes campos y disciplinas (estudios sobre políticas culturales y memoria, teorías de los discursos sociales, estudios sobre el poder y las formas de dominación social, así como el trabajo de historiadores del pasado nacional) que nos permitieron realizar una lectura crítica de los discursos y supuestos ideológicos puestos en juego.

La elección de estos modos de realizar nuestra tesina de grado en Ciencias de la Comunicación surgió a partir de la preocupación por generar materiales que permitan comprender y problematizar los procesos sociales que nos atraviesan en el presente, y que por lo tanto puedan ser difundidos y aprehendidos por diferentes actores sociales, tanto intelectuales, educadores de todos los niveles, comunicadores sociales, militantes y activistas políticos, etcétera. Nos moviliza principalmente la intención de comprender por qué la realidad es presentada como algo inexorable, como la única posible o, aún más, la mejor posible. El movimiento casi reflejo de no naturalizar realidades sociales ni construcciones que son históricamente determinadas, para poder imaginar y motorizar así otros horizontes posibles, son seguramente guías para apropiarnos de nuestro rol. En esta senda que intentamos trazar a medio camino entre lo académico y la intervención política tienen para nosotros una singular importancia las huellas que dejaron, y aún continúan dejando, la propia participación en espacios políticos surgidos en el contexto de crisis de los años 2001 y 2002, específicamente en medios de comunicación 
alternativos, asambleas barriales y movilizaciones estudiantiles en el ámbito de la universidad pública, experiencias que envueltos en la urgencia de los conflictos buscaban siempre construir prácticas y sentidos transformadores de lo existente. Esto nos permite reapropiarnos con convicción de los planteos que postulan que la ciencia y el conocimiento juegan un importante papel en la construcción de escenarios que favorezcan la transformación social y el fortalecimientos de ideas políticas emancipadoras y liberadoras de toda forma de poder opresivo, lejos de la neutralidad y la mera objetividad que muchas veces de ella se pretende.

\section{Referencias}

Barthes, R. (1999). «El mito hoy». En Mitologías. Mexico: Siglo veintiuno editores.

Castoriadis, C. (1998). «Poder, política, autonomía». En El lenguaje libertario (comp. Christian Ferrer). Altamira.

Debord, G. (1967). «La separación consumada». En La Societé du Spectacle. Champ Libre, Archivo Situacionista Hispano.

Foucault, M. (2/12/1970). «El orden del discurso». Lección inaugural en el Collège de France.

García Canclini, N. (1987). «Políticas culturales y crisis de desarrollo: un balance latinoamericano». En Políticas culturales en América Latina. México: Ed. Grijalbo.

Sмiтh, A. (1997). La identidad nacional. Madrid: Trama.

Svampa, M. (2009). «Las fronteras del gobierno de Néstor Kirchner, entre la consolidación de lo viejo y las aspiraciones de lo nuevo». En Cambio de época, movimientos sociales y poder político. Buenos Aires: Siglo XXI Editores.

YúDICE, G. (2002). «Introducción». En El recurso de la cultura. Barcelona: Gedisa. 
